\title{
Digital Colleague Connectedness: A Framework for Studying Teachers' Professional Network Interactions
}

\author{
Darci J. Harland, PhD \\ Walden University, Minneapolis, Minnesota, United States \\ (iD) https://orcid.org/0000-0001-9300-434X
}

Contact: darci.harland@mail.waldenu.edu

\section{Abstract}

The coronavirus outbreak will likely highlight both strengths and weaknesses of the pre-corona educational system. Researchers have a responsibility to examine the experiences educators have had during the pandemic; however, there are no education-specific frameworks for researchers to use to examine teachers interacting with digital colleagues for professional purposes. This paper describes the literature used to design the digital colleague connectedness framework. The purpose of the framework is to operationalize terminology used to examine educators interacting in professional exchanges within a virtual network. This framework includes six behaviors in which digital colleagues engage and four roles they may assume that specify their level of connectedness. Suggestions for how the framework might be used in future research are included.

Keywords: professional learning communities; professional learning networks; online spaces; virtual connectedness; sense of community; teacher professional development; online professional development; virtual networks; online behavior; virtual roles

Date Submitted: May 29, 2020 | Date Published: November 16, 2020

\section{Recommended Citation}

Harland, D. (2020). Digital colleague connectedness: A framework for studying teachers' professional network interactions. Journal of Educational Research and Practice, 10, 393-403. https://doi.org/10.5590/JERAP.2020.10.1.25

\section{Introduction}

Having to move learning online to accommodate the social distancing required by the COVID-19 outbreak in the spring of 2020 will likely highlight both strengths and weaknesses of the pre-COVID-19 educational system. While research shows that some teachers gravitate toward traditional face-to-face professional development, others seek informal professional development in the form of online professional networking (Romeu-Fontanillas et al., 2020). Many districts may have provided their own professional development for teachers during the quick shift to virtual learning; however, it is likely that countless teachers began to explore virtual professional networks (PN) as a way to support their own learning and to gain not only pedagogical and technology support, but also emotional support. The innovators in education have been active in PNs for years (Couros, 2015) and this untapped resource of individuals will likely have insights into how to best support teachers in times of extreme change and how this might influence how schools "do" education in the 
future. Previous research has shown that teachers benefit from PNs as a way to deal with affective, social, cognitive, and teacher identity issues (Trust et al., 2016). It is possible that the pandemic of 2020 may have encouraged more teachers to explore virtual avenues for their own professional development. Therefore, educational researchers have a responsibility to seek out and understand teacher experiences, and that purports exploring what teachers discuss in virtual spaces with one another.

Educational researchers have studied the phenomenon of teachers gathering virtually for professional purposes using a variety of terms. Professional development (or learning) networks are a "system of interpersonal connections and resources that support informal learning" (Trust, 2012) and a term that has been used to examine experiences of university faculty (Trust et al., 2017), preservice teachers (Kearney et al., 2020), and inservice teachers (Greenhalgh et al., 2020). Another popular framework is communities of practice (CoP), which is a grouping of individuals who interact regularly regarding similar concerns or passions for a specific topic (Wenger, 1998). Although the CoP framework is popular in business and industry, it has been applied to frame a wide range of educational research, from studying interactions within a MOOC course (Bozkurt \& Keefer, 2018) to exploring why teachers go online for professional development (Hur \& Brush, 2009). CoP has also been used to explore how teachers use social media for professional development. These include blogs (Yang, 2009) and Twitter (Kulavuz-Onal, 2015; Moreillon, 2015; Rosell-Aguilar, 2018). Researchers sometimes use the term virtual communities of practice (VCoP) (Hsin Hsin et al., 2016; Peeters \& Pretorium, 2020) to describe online professional development opportunities.

Kozinets (2020) asserted that the "age of virtual community" is an outdated term and a perspective that does not coincide well with modern virtual interactions. He provided several lenses for researchers to use for exploring virtual experiences. According to Kozinets, consociality is the co-presence of social actors in a network where the focus is on what is shared, rather than who the individuals are. He uses the term intersectionality to describe the crossing of axes where individuals engage in conversation and interaction, providing researchers with a construct for exploring the social positioning of individuals as they communicate through social media (p. 118). This networked individualism perspective allows researchers to focus on the structures and patterns of relationships between social actors in a network (p. 120).

The terms researchers choose for the virtual individuals they study are influenced by their discipline and methodology. For example, information technology researchers use the term "users" (Fischer, 2011), while education researchers commonly use the term "community members" (Bostancioglu, 2018). Sociologists, marketing researchers, and ethnographers use the term "social actors" (Boellstorff et al., 2012; Poschmann \& Goldenstein, 2019).

For educational researchers wanting to examine those who gather virtually, I posit that the term "digital colleague" (DC) may more accurately describe individuals interacting for professional purposes. A DC is an individual who is virtually present and in a position to communicate and interact with others on topics related to their profession. These individuals may or may not know one another in real life, but they choose to read, view, and possibly respond to each other's ideas related to their profession. A DC may publicly comment or react to another DC's ideas or contribute new ideas seeking input and interaction; however, even those who are invisible, only reading, are still considered DCs.

\section{Virtual Network Behaviors}

When applying Kozinets's (2020) consociality to virtual network interactions of DCs, it is important to describe the behaviors of the professional interactions. In a sociology study of scientists on Twitter, researchers took an innovative approach and, in addition to examining the topics of engagement, they examined the directions and modes of engagement (Jünger \& Fähnrich, 2019). Some of the modes of engagement behaviors included reporting, commenting, reputational, participatory, activating, and 
inspirational, but researchers found it was important to pay attention to whether the scientist referenced others, referenced self, or added mentions in the posts. Jünger and Fähnrich (2019) described virtual behaviors that have yet to be explored in educational research. Another way virtual behaviors are studied is the use of social network analysis (SNA). SNA provides a graphical representation of individuals' interactions with others and within a network (Fenton \& Procter, 2019). In a mixed method study, seven teachers were interviewed about how their interactions on Twitter and on blogs helped them solve classroom problems (Smith Risser et al., 2019). Teacher participants described their behaviors, and researchers compared this to teachers' virtual behaviors using SNA to look at network measures and to examine social capital. The authors admitted that comparing what teachers say they experience may not necessarily match the SNA data collected on teachers' interactions. Smith Risser et al. highlighted the challenge of studying teachers' virtual interactions and acknowledged that "offline networks" influence teachers in tandem with virtual networks (p. 281). In an information systems study, Cranefield et al. (2015) identified a number of observable behaviors within a networked community. Interactions included "signaling availability, helpdesking, building up ideas, affirming, buddying, intervening, soliciting, matchmaking, and championing tool use” (p. 228). These interactions are observable and, therefore, helpful descriptions that may be generalizable in future research.

\section{Individual Roles and Connectedness}

Most frameworks or models used for examining groups of individuals interacting virtually focus on the roles the individuals assume within the network. The four C's of participation (Trust, 2017) is an existing framework that was developed through research on the virtual professional development of teachers. Trust identified four types of participators, the contemplator, curator, crowdsourcer, and contributor, each describing what teachers do within a network. However, these descriptions are linked to teacher behaviors that likely overlap. For example, a crowdsourcer who posts a request for action and consolidates the knowledge from the crowd to identify a solution or resource may likely also "read and assess the shared knowledge," which is participation associated with a contemplator (p. 106). Categorizing teacher roles without acknowledging the fluidity of teacher behaviors within the network render the four $\mathrm{C}$ participation labels problematic for research.

Although not developed specifically for education, the richer ecologies of participation framework developed by a computer scientist contribute to the understanding of participation between individuals interacting virtually (Fischer, 2011). The framework has four levels, described as consumers, contributors, collaborators, and meta-designers, defined by distinct roles based on "different levels of expertise, interests, and motivations" (p. 45). The problem is that levels of expertise, interests, and motivation are not always observable. Therefore, in addition to observing interactions, data must also be collected via surveys where members of a network self-report their interactions (Carpenter \& Krutka, 2015), by SNA (Fantinelli \& Russo, 2018), or digital traces (Staudt Willet, 2019). However, additional research is needed to further explore behaviors within frameworks like Trust's (2017), as well as the established CoP framework (Wenger, 1998) and network role in order to modernize a more applicable framework to describe virtual PNs.

The purpose of a new framework is first to provide common terminology for educational researchers to use when examining PNs of teachers, rather than borrowing language from the fields of marketing, sociology, or information technology. Second, a new framework is needed to separate what DCs may do when they interact virtually from the role or connectedness they have at the time. A more flexible framework may allow a more accurate representation of virtual interactions by separating behaviors from roles that DCs assume while interacting. 


\section{Introduction to the Digital Colleague Connectedness Framework}

The purpose of the digital colleague connectedness (DCC) framework is to operationalize the terminology used to examine educators interacting virtually and engaging in professional exchanges within a network. The framework was developed to separate DC behaviors from their roles. This framework includes six behaviors with which DCs engage when interacting with other DCs. The second part includes four roles DCs may assume that specify their levels of connectedness.

\section{Behavior}

The first part of the DCC framework is related to a DC's behavior. When studying sociality, it is critical that researchers describe what educators do when interacting with other professionals (Kozinets, 2020). Virtual interactions ebb and flow, rarely taking linear trajectories of participation. Instead, DCs engage in many different behaviors regardless of the levels of connectedness they may currently function within. These behavior categories may be used to group types of interactions for analysis, looking for themes across many DC interactions. The behaviors might also be used to describe a DC's current interaction behavior or to help log DCs' behaviors over longer periods of time. Six categories make up the behavior portion of the framework. See Table 1.

\section{Lurk and React}

"Lurk and react" is when a DC is co-present with other DCs but contributes little or nothing that is visible. In this framework, the term lurk refers to a behavior or action, not a role. Many individuals lurk for a time before they decide to contribute (Cranefield et al., 2015). Lurking actions are not visible, as an individual is either inwardly-focused on content (Koutropoulos et al., 2019), learning site navigation (Honeychurch et al., 2017), or becoming acquainted with social norms of the network (Matyas, 2017). While not visible, lurking includes any number of invisible activities, such as filtering, identifying and following, and classifying (Cranefield et al., 2015). An action that is visible for this category of behavior includes single-click actions, such as sharing (with no additional comments), posting an emoticon, or a "like" as a way to quickly communicate that a contribution was read and appreciated. Liking and sharing have been attributed as lurking behavior in other education research and have shown to be critical for the network as content created by others is amplified (Koutropoulos et al., 2019). Additionally, lurk and react is the most common behavior for all DCs as each searches and makes decisions on where and how to contribute within the network.

\section{Consume}

The "consume" behavior refers to times when a DC reads and follows up on content. Consume is only slightly different from a lurk and react behavior in that it goes beyond just reading and includes a form of eliciting additional information posted by DCs. For example, a post that represents consume behavior would be a follow-up question to DC's post or a one-to-many request posted to a larger group of DCs seeking resources or answers. Consume behavior is a type of soliciting or requesting virtual contribution (Cranefield et al., 2015). The purpose of the consume behavior is to find resources and solutions quickly.

\section{Promote}

DCs who promote products, services, or publicize their professional or personal brand or accomplishments are practicing the "promote" behavior. DCs promote when they post a reference or include URLs to additional information about products, services, or events. Promote behaviors include reputational posts that describe projects, publications, and professional achievements (Jünger \& Fähnrich, 2019). Posts that promote are meant to reach a large number of DCs. DC replies to posts that promote or answer questions, further promoting or publicizing. Promote is not a behavior that has been explored in educational research. While some DCs have commanding professional footprints, little empirical research has explored teachers as entrepreneurs (Shelton \& Archambault, 2018). 
Table 1: Digital Colleague Connectedness Behaviors

\begin{tabular}{llll}
\hline Behavior & Description of behavior & What is observable \\
\hline lurk \& react & Skims content and rarely posts & - & One-click reactions (i.e., likes, emoticons) \\
& & Share with no additional comments (i.e., \\
& & forward, retweet)
\end{tabular}

\section{Inform and Inspire}

Posts with content published to "inform or inspire" the DC network can be in the form of new content created by a DC for the network, or it can be shared or linked content. Tess (2013) described these creative acts as content created or remixed to share, while inspirational posts encourage the PN (Jünger \& Fähnrich, 2019). Inspire or affirmation include giving or receiving approval, praise, and encouragement (Cranefield et al., 2015)

\section{Engage}

The behavior of "engage" refers to sharing, forwarding, or commenting on professional ideas of others, all eliciting responses and stimulating professional dialogue. Engage posts are identifiable in several ways. First, posts in the network answer questions related to philosophical or pragmatic professional topics. DCs whose posts engage through the use of tags-or the equivalent-in order to establish connection between DCs is a type of virtual matchmaking (Cranefield et al., 2015). Engage posts might also show evidence of buddying, engaging in multiple interactions with another DC; connecting people to others with common interests; or intervening, where challenges are made to engage with the PN (Cranefield et al., 2015). 


\section{Organize and Lead}

Posts with content related to DC network events or posted to establish or enforce PN norms fall under the behavior of "organize and lead." These posts often function as a way to moderate, announce, and administrate issues related to the DC network as a whole.

\section{Role/Connectedness Level}

The connectedness level that a DC assumes during interactions with other DCs is considered their role. The following four roles may be used to operationalize the connectedness journey of a single DC over time, or it may be used to categorize a DC's primary role within the network as a way to compare or examine DCs at varying levels of connectedness. See Table 2.

Table 2: Digital Colleague Role or Level of Connectedness

\begin{tabular}{|c|c|c|c|}
\hline & Role description & Connectedness & Common behaviors \\
\hline \multirow[t]{2}{*}{ Sightseer } & $\begin{array}{l}\text { Invisible; few to no virtual } \\
\text { connections }\end{array}$ & \multirow[t]{2}{*}{$\begin{array}{l}\text { Connectedness limited to single } \\
\text { click reactions }\end{array}$} & \multirow[t]{2}{*}{$\begin{array}{ll}\text { - } & \text { lurk \& react } \\
\text { - } & \text { consume }\end{array}$} \\
\hline & $\begin{array}{l}\text { May share content from DC } \\
\text { with f2f colleagues }\end{array}$ & & \\
\hline \multirow[t]{2}{*}{ Mingler } & Occasional interactions & \multirow{2}{*}{$\begin{array}{l}\text { Low connectedness related to } \\
\text { eliciting pragmatic or logistical } \\
\text { help from DCs; posts questions } \\
\text { in private or public spaces }\end{array}$} & \multirow[b]{2}{*}{$\begin{array}{ll}\text { - } & \text { lurk \& react } \\
\text { - } & \text { consume } \\
\text { - } & \text { promote } \\
\text { - } & \text { inform and inspire } \\
\text { - } & \text { engage (but in } \\
& \text { lower frequency } \\
& \text { than denizens) }\end{array}$} \\
\hline & $\begin{array}{l}\text { Connects to DCs when they } \\
\text { have needs or interests }\end{array}$ & & \\
\hline \multirow[t]{4}{*}{ Denizen } & Regularly interacts with DCs & \multirow{4}{*}{$\begin{array}{l}\text { Connects to all roles of DCs but } \\
\text { purposefully focuses on engaging } \\
\text { sightseers and minglers }\end{array}$} & \multirow{4}{*}{$\begin{array}{ll}\text { - } & \text { lurk \& react } \\
\text { - } & \text { consume } \\
\text { - } & \text { informote } \\
\text { - } & \text { engage (but in } \\
& \text { higher frequency } \\
& \text { than minglers) } \\
& \text { organize and lead } \\
& \text { (less than } \\
\text { insiders) }\end{array}$} \\
\hline & Stable contributor & & \\
\hline & $\begin{array}{l}\text { Curates content and connects } \\
\text { DCs to resources }\end{array}$ & & \\
\hline & $\begin{array}{l}\text { Actively seeks new connections } \\
\text { and initiates connections/ } \\
\text { introductions between DCs }\end{array}$ & & \\
\hline \multirow[t]{3}{*}{ Insider } & $\begin{array}{l}\text { Perpetual interactions with DCs; } \\
\text { pioneer/steer opportunities for } \\
\text { DCs to connect }\end{array}$ & \multirow{3}{*}{$\begin{array}{l}\text { Connected with insiders and } \\
\text { denizens in private and public } \\
\text { spaces but may communicate } \\
\text { with all DCs publicly and } \\
\text { frequently. }\end{array}$} & \multirow{3}{*}{$\begin{array}{ll}\text { - } & \text { lurk \& react } \\
\text { - } & \text { consume } \\
\text { - } & \text { promote } \\
\text { - } & \text { engage } \\
& \text { organize and lead }\end{array}$} \\
\hline & $\begin{array}{l}\text { Provides logistical or visionary } \\
\text { support to keep the network } \\
\text { operating smoothly }\end{array}$ & & \\
\hline & $\begin{array}{l}\text { Is the founder of the network or } \\
\text { is seen as equals within the } \\
\text { network with the founder }\end{array}$ & & \\
\hline
\end{tabular}




\section{Sightseer}

Although not always visible, a "sightseer" engages primarily with lurk and react behaviors. Sightseers, often referred to as lurkers in other research, are usually silent within the DC network, but may be engaging mutely, while establishing invisible social ties (Koutropoulos et al., 2019). However, they may be critical curators of educational content posted by DCs (Sawyer et al., 2016), just not posting publicly. For example, they may take content accessed through the DC network and share it with face-to-face colleagues (Cranefield et al., 2015), but not contribute or comment in a way that is visible within the network or by researchers for that matter. Sightseers might be viewed as being on the periphery as described by Wenger's CoP (1998), but their numbers make up the largest percentage of participants within virtual communities (Matyas, 2017) and, therefore, should not be dismissed as irrelevant to a DC network. Neither should sightseers be associated with a negative connotation, because DCs in this role frequent the network to tap into professional resources and to explore whether or not to engage in other ways.

\section{Mingler}

A DC who occasionally participates in a PN when they want to elicit pragmatic or logistical knowledge is called a "mingler." Minglers seek answers that will meet an immediate professional interest, need, or goal, like Trust's (2017) category of curator and, as such, often exhibit lurk and react and consume behaviors. Minglers are aware of content availability and more readily share information as they become more aware of the resources and the variety of interaction possibilities. Like follower-feeders (Cranefield et al., 2015), minglers have followers and seek new DCs with whom they may connect, moving between invisible and visible behaviors within the network. They may show behaviors such as promoting, informing and inspiring, and engaging. However, they exhibit these behaviors in lower frequencies than denizens, the next category. A mingler's behaviors of DCs may flux between sightseeing and back to mingler, much like the occasional participant within Wenger's CoP framework (1998).

\section{Denizens}

A "denizen" is a DC who regularly frequents the network. A denizen is a stable contributor, such as active participants in the CoP framework (Wenger, 1998), connector-leader (Cranefield et al., 2015), or contributor in the $4 \mathrm{C}$ framework (Trust, 2017). Denizens often curate content and help DCs connect to both content and one another. They are conversation starters (Cranefield et al., 2015), highly visible and viewed by other DCs as well-connected. Denizens exhibit lurk and react, consume, promote, inform and inspire, and engage behaviors and do so more often than sightseers or minglers. Denizens occasionally display the behavior of organize and lead, most often when they moderate or host discussions or virtual events for DCs, but do so less than insiders, the last role category.

\section{Insiders}

An "insider" is a DC who has perpetual interactions with DCs. Insiders are either the founders of the network or seen as equals with the founders (Britt \& Paulus, 2016), similar to Wenger's (1998) category of core participants in the CoP framework, or global leader in Cranefield et al.'s framework (2015). Insiders pioneer and steer opportunities for DCs to connect. They provide logistical and/or visionary support to keep the PN operating smoothly, acting as stewards of technology or knowledge (Enríquez et al., 2019). Insiders may connect with other insiders and denizens in private spaces to delegate tasks and discuss DC network logistics. They display all behaviors but engage in the behavior of organize and lead considerably more than denizens.

\section{Applying the Framework}

The DCC framework could be used by researchers in any number of ways. For instance, teacher behaviors in their PNs could be categorized to identify their roles and then examined to see how DCs differed in the depth at which they reflect on teaching and learning. Or, after engaging as a participant observer, a netnographer might use their observations of DC interactions to categorize educators at varying levels of connectedness in 
order to purposefully sample for DCs to interview. While the behavior and role constructs are complementary and were designed to be used together, they may also be used in isolation depending on the purpose of the study. For example, a qualitative researcher might conduct a content analysis of DCs' Twitter posts and code the tweets by DCC behaviors, and then look for emergent themes within each. A researcher might bind a case study by the level of connectedness in order to explore DC interactions in PNs such as Pinterest, Teachers Pay Teachers, or LinkedIn. Data sources could come from the content analysis of text, media, and graphics, interviews, or reflective journals. Mixed method researchers might tag DCC behaviors using SNA to examine discussion interactions in higher education. The DCC framework was constructed to help educational researchers extend what is understood about how a teacher's connectedness influences, or is influenced by, any number of factors.

\section{Social Change}

With $\mathrm{K}-12$ and higher education instructors having had to move their teaching online, no better time exists to examine the social positioning of teachers who have been asked to teach in physical isolation and without the traditional face-to-face PD. It is likely that teachers, more than ever, will reach out virtually to colleagues for support during this unique time in the history of education. Teacher PNs may be rich with data that could inform decision-making, possibly providing insight on how to create a better balance of physicality and technology in future classrooms. Therefore, educational researchers should seize this opportunity to understand teachers' pandemic teaching experiences by exploring how teachers interact in their PNs and what insights are collectively generated about the future of teaching and learning. 


\section{References}

Boellstorff, T., Nardi, B., Pearce, C., \& Taylor, T. L. (2012). Ethnography and virtual worlds: A handbook of method. Princeton University Press.

Bostancioglu, A. (2018). Online communities of practice in the service of teachers' technology professional development: The case of webheads in action. The Turkish Online Journal of Educational Technology, $17(2)$.

Bozkurt, A., \& Keefer, J. (2018). Participatory learning culture and community formation in connectivist MOOCS. Interactive Learning Environments, 26(6), 776-788. https://doi.org/10.1080/10494820.2017.1412988

Britt, V. G., \& Paulus, T. (2016). "Beyond the four walls of my building”: A case study of \# edchat as a community of practice. American Journal of Distance Education, 30(1), 48-59. https://doi.org/10.1080/08923647.2016.1119609

Carpenter, J. P., \& Krutka, D. G. (2015). Social media in teacher education. In M. L. Niess \& H. Gillow-Wiles (Eds.), Handbook of research on teacher education in the digital age (pp. 28-54). IGI Global. https://doi.org/10.4018/978-1-4666-8403-4.cho02

Couros, G. (2015). Innovator's mindset: Empowering learning, unleash talent, and lead a culture of creativity. Dave Burgess Consulting, Inc.

Cranefield, J., Yoong, P., \& Huff, S. L. (2015). Rethinking lurking: Invisible leading and following in a knowledge transfer ecosystem. Journal of the Association for Information Systems, 16(4), 213-247.

Enríquez, S. C., Gargiulo, S. B., Ponz, M. J., \& Scorians, E. E. (2019). Virtual communities of practice in the future of education. In J. W. Moravec (Ed.), Emerging Education Futures, pp: 83-100. Education Futures.

Fantinelli, S., \& Russo, V. (2018). Community of practice online, the importance of technology for learning: An application of social network analysis. Journal of e-Learning and Knowledge Society, 14(3). https://doi.org/10.20368/1971-8829/1545

Fenton, A., \& Procter, C. T. (2019). Studying social media communities: Blending methods with netnography. Research Methods Cases, 1-19. https://doi.org/10.4135/9781526468901

Fischer, G. (2011). Understanding, fostering, and supporting cultures of participation Interactions, 18(3), 4253. https://doi.org/10.1145/1962438.196245

Greenhalgh, S. P., Rosenberg, J. M., Willet, K. B. S., Koehler, M. J., \& Akcaoglu, M. (2020). Identifying multiple learning spaces within a single teacher-focused twitter hashtag. Computers \& Education, 103809. https://doi.org/10.1016/j.compedu.2020.103809

Honeychurch, S., Bozkurt, A., Singh, L., \& Koutropoulos, A. (2017). Learners on the periphery: Lurkers as invisible learners. European Journal of Open, Distance and e-Learning, 2O(1). https://doi.org/10.1515/eurodl-2017-0012

Hsin Hsin, C., Hsieh, P.-H., \& Fu, C. S. (2016). The mediating role of sense of virtual community. Online Information Review, 40(7), 882-899. https://doi.org/10.1108/OIR-09-2015-0304

Hur, J. W., \& Brush, T. A. (2009). Teacher participation in online communities: Why do teachers want to participate in self-generated online communities of $\mathrm{K}-12$ teachers? Journal of Research on Technology in Education, 41(3), 279-303. https://doi.org/10.1080/15391523.2009.10782532

Jünger, J., \& Fähnrich, B. (2019). Does really no one care? Analyzing the public engagement of communication scientists on Twitter. New Media \& Society, 1-22.

https://doi.org/10.1177/1461444819863413 
Kearney, M., Maher, D., \& Pham, L. (2020). Investigating pre-service teachers' informally-developed online professional learning networks. Australasian Journal of Educational Technology, 36(1), 21-36.

Koutropoulos, A., Honeychurch, S., \& Singh, L. (2019, May). Rethinking lurking. eLearn Magazine. https://elearnmag.acm.org/archive.cfm?aid=3331169

Kozinets, R. (2020). Netnography: The essential guide to qualitative social media research. SAGE.

Kulavuz-Onal, D. (2015). Using netnography to explore the culture of online language teaching communities. Computer Assisted Language Instruction Consortium Journal, 32(3). https://doi.org/10.1558/cj.v32i3.26636

Matyas, M. L. (2017). Lurk or lead? The benefits of community participation. Advanced Physiology Education, 41, 145-148. https://doi.org/10.1152/advan.00200.2016

Moreillon, J. (2015). \#schoollibrarians tweet for professional development: A netnographic case study of \#txlchat. School Libraries Worldwide, 21(2), 127-137. DOI: 10.14265.21.2.010

Peeters, W., \& Pretorium, M. (2020). Facebook or fail-book: Exploring "community" in a virtual community of practice. ReCALL FirstView, 1-16. https://doi.org/10.1017/S0958344020000099

Poschmann, P., \& Goldenstein, J. (2019). Disambiguating and specifying social actors in big data: Using Wikipedia as a data source for demographic information. Sociological Methods \& Research. https://doi.org/10.1177\%2Fo049124119882481

Romeu-Fontanillas, T., Guitert-Catasús, M., Raffaghelli, J., Sangrà, A., Romeu-Fontanillas, T., GuitertCatasús, M., Raffaghelli, J., \& Sangrà, A. (2020). Mirroring learning ecologies of outstanding teachers to integrate ICTS in the classroom. Comunicar, 62(23), 31-42. https://doi.org/10.3916/C62-2020-03.

Rosell-Aguilar, F. (2018). Twitter: A professional development and community of practice tool for teachers. Journal of Interactive Media in Education, 1(6), 1-12. https://doi.org/10.5334/jime.452

Sawyer, A. G., Dredger, K., Myers, J., Barnes, S., Wilson, R., Sullivan, J., \& Sawyer, D. (2016). Developing teachers as critical curators: Investigating elementary preservice teachers' inspirations for lesson planning. Journal of Teacher Education, 71(5), 518-536. https://doi.org/10.1177/0022487119879894

Shelton, C., \& Archambault, L. (2018). What does it mean to be an online teacherpreneur? A qualitative investigation of highly experienced and successful authors on Teacher Pay Teachers. In E. Langran \& J. Borup (Eds.), Proceedings of Society for Information Technology \& Teacher Education International Conference, pp. 1724-1728. Association for the Advancement of Computing in Education.

Smith Risser, H., Bottoms, S., \& Clark, C. (2019). "Nobody else organized": Teachers solving problems of practice in the twitterblogosphere. Educational Media International, 56(4), 269-284. https://doi.org/10.1080/09523987.2019.1681111

Staudt Willet, K. B. (2019). Revisiting how and why educators use Twitter: Tweet types and purposes in \# edchat. Journal of Research on Technology in Education, 51(3), 273-289. https://doi.org/10.1080/15391523.2019.1611507

Tess, P. A. (2013). The role of social media in higher education classes (real and virtual)-a literature review. Computers in Human Behavior, 29(5), A60-A68. https://doi.org/10.1016/j.chb.2012.12.032

Trust, T. (2012). Professional learning networks designed for teacher learning. Journal of Digital Learning in Teacher Education, 28(4), 133-138.

Trust, T. (2017). Using cultural historical activity theory to examine how teachers seek and share knowledge in a peer-to-peer professional development network. Australian Journal of Educational Technology, 33(1). https://doi.org/10.14742/ajet.2593 
Trust, T., Carpenter, J. P., \& Krutka, D. G. (2017). Moving beyond silos: Professional learning networks in higher education. The Internet and Higher Education, 35, 1-11.

https://doi.org/10.1016/j.iheduc.2017.06.001

Trust, T., Krutka, D. G., \& Carpenter, J. P. (2016). "Together we are better": Professional learning networks for teachers. Computers \& Education, 102, 15-34. https://doi.org/10.1016/j.compedu.2016.06.007

Wenger, E. (1998). Communities of practice: Learning, meaning, and identity. Cambridge University Press.

Yang, S.-H. (2009). Using blogs to enhance critical reflection and community of practice. Journal of Educational Technology \& Society, 12(2), 11-21.

The Journal of Educational Research and Practice is a peerreviewed journal that provides a forum for studies and dialogue about developments and change in the field of education and learning. The journal includes research and related content that examine current relevant educational issues and processes. The aim is to provide readers with knowledge and with strategies to use that knowledge in educational or learning environments. JERAP focuses on education at all levels and in any setting, and includes peer-reviewed research reports, commentaries, book reviews, interviews of prominent individuals, and reports about educational practice. The journal is sponsored by the Richard W. Riley College of Education and Leadership at Walden University, and publication in JERAP is always free to authors and readers. 